\title{
Stent Redilation in Canine Models of Congenital Heart Disease: Pulmonary Artery Stenosis and Coarctation of the Aorta
}

\author{
Alan M. Mendelsohn, MD, Parvin C. Dorostkar, MD, Catherine P. Moorehead, MS, \\ Flavian M. Lupinetti, MD, Paul I. Reynolds, MD, Achi Ludomirsky, MD, Thomas R. Lloyd, MD, \\ Kathleen Heidelberger, MD, and Robert H. Beekman III, MD

\begin{abstract}
In a canine puppy model, pulmonary artery stenosis was created by banding the lett pulmonary artery to $30-40 \%$ of its original diameter. Animals underwent right heart catheterization and angiography 1-2 mo later, and Palmaz P308 stents were implanted. Stent redilation was performed 3-5 mo later. One mo postredilation, the animals were restudied and sacrificed. Coarctations of the aorta were created by transverse aortic incislon and longitudinal repair. P308 stent implantation was performed 2-3 mo later. Stent redilation was performed after $6-10 \mathrm{mo}$, and the animals were restudied and sacrificed 1-2 mo later.

Stent implantation was performed in 6 puppies with pulmonary artery stenosis, as 2 animals developed postoperative pulmonary arterial hypoplasia, precluding stenting. The stenosis diameter increased from $4.8 \pm 0.5 \mathrm{~mm}$ to $7.4 \pm 0.6 \mathrm{~mm}$ (mean $\pm S E$ ) following stenting ( $P=0.005$ ), and increased further to $9.2 \pm 0.7 \mathrm{~mm}$ following redilation $(P$ $0.001)$. There were no significant vessel tears or ruptures. Coarctation stenting was performed in 8 animals. The coarctation was dilated from $5.8 \pm 0.9 \mathrm{~mm}$ to $9.8 \pm 0.6 \mathrm{~mm}$ ( $P$ $0.001)$, and to $13.5 \pm 0.5 \mathrm{~mm}$ at redilation $(P=0.002)$. Redilation could not be performed in 1 animal. Aortic rupture and death occurred in 2 of 7 animals at redilation.

Stent implantation and redilation in experimental pulmonary artery stenosis appears safe and effective. Though stent implantation for coarctation of the aorta appears safe, there was a $28 \%$ aortic rupture rate at stent redilation in this model.
\end{abstract} \\ 1996 Wiley-Liss, Inc.
}

Key words: endovascular stents, aortic coarctation, peripheral pulmonary stenosis

\section{INTRODUCTION}

Endovascular stent therapy has become an important interventional technique in the treatment of congenital and acquired pulmonary artery stenosis and right ventricular outflow tract obstruction, particularly in the postoperative patient [1-4]. There has been little application of this technique to congenital aortic anomalies such as coarctation of the aorta $[5,6]$. The utility of stent therapy in the pediatric population may be limited, however, by the need to redilate these stainless steel stents in a growing child. There are few data addressing the potential for stent redilation in normal [7] or abnormal [6] vessels. The objectives of this study, therefore, were to demonstrate the safety and effectiveness of stent redilation in young animal models of pulmonary artery stenosis and coarctation of the aorta, and to evaluate the gross anatomic and histologic results of stent redilation.

\section{METHODS}

\section{Pulmonary Artery Studies}

Pulmonary artery stenosis creation. Our technique for peripheral pulmonary artery stenosis creation has pre- viously been described [8]. Briefly, in 8 mongrel puppies (weight $800 \mathrm{~g}$ ), general endotracheal anesthesia was induced, using halothane. A left thoracotomy was performed, and the left pulmonary artery was banded 1-2 $\mathrm{cm}$ from its origin, using two loops of 2-0 vicryl suture. The pulmonary artery was narrowed to $30-40 \%$ of its original diameter. All animals received 3 days of intramuscular antibiotics and pain medications as necessary.

Pulmonary artery stenting. After a 1-2-mo recovery

From the Divisions of Pediatric Cardiology, Cardiovascular Surgery, Anesthesia, and Pathology, C.S. Mott Children's Hospital, University of Michigan Medical Center, Ann Arbor, Michigan.

Received November 20, 1995; revision accepted February 20, 1996.

This study was presented in part at the 43rd Annual Scientific Sessions, American College of Cardiology, Atlanta, Georgia, March 1317, 1994.

Address reprint requests to Dr. Alan M. Mendelsohn, currently at Children's Hospital Medical Center, 3333 Burnet Ave., Cincinnati, OH 45229. 
period, the animals underwent percutaneous hemodynamic and angiographic studies under surital anesthesia. Our technique for pulmonary artery stenting has been previously described [8]. Briefly, a Palmaz P308 stent (Johnson \& Johnson Interventional Systems, Warren, NJ) was loaded onto a standard low-pressure balloon angioplasty catheter (NuMed, Inc., Hopkinton, NY; Mansfield Scientific, Mansfield, MA) chosen to yield a balloon to stenosis ratio of between 2-3:1. Measurements of stenoses and stent dimensions were made by two investigators (A.M.M., R.H.B.) using the angiographic catheter as a standard measure. In all cases, balloon diameters between $8-10 \mathrm{~mm}$ were used. The balloon was inflated to the maximal pressure of 4-7 atm. Repeat single-plane angiography and pressure measurements were performed following stent implantation with a standard endhole catheter. The animals received 3 days of intramuscular antibiotics and morphine sulfate for pain as indicated.

Stent redilation. The animals underwent stent redilation 3-5 mo following stent implantation. Complete right heart hemodynamic and angiographic studies were performed via percutaneous femoral venous access. A 7 Fr endhole catheter was advanced through the stent to the distal left pulmonary artery. In all cases, a standard 12-mm low-pressure angioplasty balloon (Nu Med, Inc.; Mansfield Scientific) was advanced over a $250-\mathrm{cm}$ $0.035^{\prime \prime}$ guidewire to the stent, and the stent was redilated using 4--5 atm balloon pressure. Repeat pressure measurements and single-plane angiography were performed. One animal was sacrificed immediately following stent redilation. The other animals recovered and were treated postoperatively as previously noted. Chronic antiplatelet or anticoagulation therapy was not employed. The animals were sacrificed 1 mo postredilation. Gross and histologic tissue examination was then undertaken.

\section{Coarctation Studies}

Coarctation creation. In 16 mongrel puppies general endotracheal anesthesia was induced with halothane anesthesia. Through a left lateral thoracotomy, the upper descending aorta distal to the left subclavian artery was isolated. The aorta was clamped longitudinally with incomplete aortic occlusion, and a transverse incision of approximately $50 \%$ of the diameter of the aorta was made. The incision was then repaired longitudinally using 5-0 polypropylene running sutures. The animals received 3 days of intramuscular antibiotics and morphine sulfate for pain as indicated.

Coarctation stenting. Stent implantation was performed 2-3 mo following coarctation creation. The right femoral artery was cannulated with a $7 \mathrm{Fr}$ sheath via cutdown, and a $7 \mathrm{Fr}$ Berman angiographic catheter was then advanced across the coarctation. Following pressure measurements and angiography, the $7 \mathrm{Fr}$ sheath and catheter were exchanged for a $10 \mathrm{Fr} 80-100-\mathrm{cm}$ length sheath (Cook Inc., Indianapolis, IN). Measurements of coarctation, isthmus, and stent diameters were made by two investigators (A.M.M., R.H.B.), using the angiographic catheter as a standard marker. A Palmaz P308 stent was loaded onto a standard low-pressure angioplasty balloon chosen to yield a balloon-to-isthmus ratio of approximately 1.0. The stent/balloon was positioned across the coarctation and inflated to 4-7 atm. Postimplantation single-plane angiograms were then performed. The femoral arteries were repaired with 6-0 absorbable suture, and the animals received standard regimens of antibiotics and pain medications.

Stent redilation. Stent redilation was performed 6-10 mo after stent implantation via cutdown of the left femoral artery. A balloon-to-isthmus ratio of approximately 1.0 was chosen for redilation, and the stent was redilated at low pressure (4-7 atm). After redilation, chronic antiplatelet or anticoagulation therapy was not used. Follow-up single-plane angiography and hemodynamic measurements were performed 1-2 mo postredilation, and the animals were sacrificed for gross anatomic and histologic examination.

Statistics. All data are expressed as mean $\pm 1 \mathrm{SE}$ of the mean. Acute changes in gradient and stent diameter were evaluated by paired Student's $t$-tests. Serial comparisons were evaluated by repeated measures analysis of variance. Statistical significance was accepted at $P<$ 0.05 .

\section{RESULTS}

\section{Pulmonary Artery Stenosis}

Pulmonary artery stenting (Table I). All 8 puppies survived pulmonary artery banding. Angiography performed prior to stent implantation disclosed 2 animals with severe left pulmonary artery hypoplasia or atresia which precluded attempts at stent implantation. At time of stent implantation, the animals weighed $30 \pm 1.8 \mathrm{~kg}$ (range, 22-33.5 kg). Stent implantation was performed in the 6 animals using a balloon-to-stenosis ratio of 2.0 \pm 0.2 (range, 1.6-2.7). Following stent implantation, stenosis diameter increased from $4.8 \pm 0.5 \mathrm{~mm}$ (range, $3.4-6.3 \mathrm{~mm}$ ) to $7.4 \pm 0.6 \mathrm{~mm}$ (range, $5.1-9.4 \mathrm{~mm})(P$ $=0.005$ ), and diameter of the pulmonary artery proximal to the stenosis (at the proximal stent) increased from $7.3 \pm 0.6 \mathrm{~mm}$ (range, $5.4-8.8 \mathrm{~mm}$ ) to $9.6 \pm 0.4 \mathrm{~mm}$ (range, $7.9-10.7 \mathrm{~mm})(P=0.004)$ (Fig. 1). There was no angiographic or clinical evidence of pulmonary artery rupture, aneurysm, or dissection (Fig. 2A). In one animal, flow to a small left upper lobe branch which was crossed by the stent appeared compromised but still had 

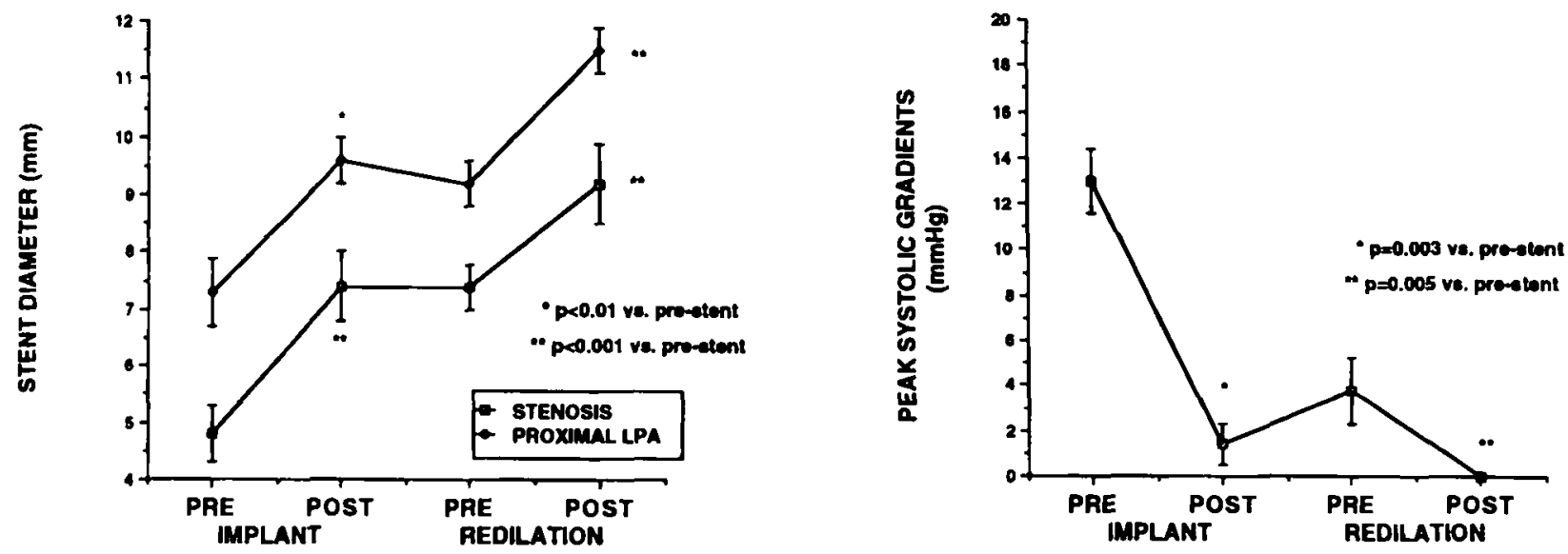

Fig. 1. Line graph of changes in pulmonary antery stent diameter (left) and peak systolic pressure gradient (right), both at stent implantation and at redilation. Stenosis, left pulmonary artery at level of banding. Proximal LPA, region of left pulmonary artery proximal to stenotic region.

a small amount of antegrade flow. Otherwise, all other pulmonary artery branches were angiographically patent. The peak systolic pressure gradient of $13 \pm 1.4 \mathrm{~mm} \mathrm{Hg}$ across the stenosis prior to stent implantation (range, $10-17 \mathrm{~mm} \mathrm{Hg})$ was reduced to $1.4 \pm 0.9 \mathrm{~mm} \mathrm{Hg}(0-4$ $\mathrm{mm} \mathrm{Hg}).(P=0.003)$ following stent implantation.

Pulmonary artery stent redilation. The 6 experimental animals underwent stent redilation $3.8 \pm 0.2$ mo poststent implantation. The animals' weight was $46.3 \pm$ $3.2 \mathrm{~kg}$ (range, 31-52 kg), which represents a $54 \pm 3 \%$ increase in weight from stent implantation $(P<0.001)$. All stents were redilated using a $12-\mathrm{mm}$ low-pressure angioplasty balloon. Two of the 6 stents protruded into the main pulmonary artery and could not crossed. These 2 animals were sacrificed, and the left pulmonary artery stent was redilated ex vivo (Table I, animals 2 and 3 ).

The stenosis was effectively redilated from $7.4 \pm 0.4$ $\mathrm{mm}$ (range, $5.7-8.6 \mathrm{~mm}$ ) to $9.2 \pm 0.7 \mathrm{~mm}$ (range, $8.1-10 \mathrm{~mm})(P<0.001)$, and the diameter of the left pulmonary artery proximal to the stenosis increased from $9.2 \pm 0.4 \mathrm{~mm}$ (range, $7.7-10 \mathrm{~mm}$ ) to $11.5 \pm 0.4 \mathrm{~mm}$ (range, $10.4-12.8 \mathrm{~mm})(P=0.002)$. A small residual gradient of $3.8 \pm 1.5 \mathrm{~mm} \mathrm{Hg}$ (range, $0-8 \mathrm{~mm} \mathrm{Hg}$ ) was completely obliterated by stent redilation (Fig. 1). There was concomitant increase in the unbanded and unstented right pulmonary artery from $11.9 \pm 0.7 \mathrm{~mm}$ at the time of left pulmonary artery (LPA) stenting to $14.3 \pm 0.9$ at LPA stent redilation $(P=0.04)$. Stent length decreased from $27.4 \pm 0.9 \mathrm{~mm}$ to $25.7 \pm 0.8 \mathrm{~mm}$ following stent redilation $(P=0.01)$. There were no acute tears, vessel ruptures, or arterial dissections identified by follow-up angiography (Fig. 2B). In the one animal in whom flow to a small upper lobe vessel appeared obstructed after stent implantation, no further obstruction to flow was noted.

\section{Coarctation of Aorta}

Coarctation stent implantation (Table II). Only 8 of the initial 16 puppies survived creation of the coarctation. Stent implantation was performed in these 8 animals 2-3 mo following surgery, when the animals weighed $13.8 \pm 1.3 \mathrm{~kg}$ (range, 9.5-19 kg). Balloon diameters varied from $10-15 \mathrm{~mm}$, yielding a balloon-toisthmus ratio of $1.07 \pm 0.07$ (range, $0.93-1.1$ ). The coarctation was dilated from $5.8 \pm 0.9 \mathrm{~mm}$ (range, 3.7 $9.5 \mathrm{~mm}$ ) to $9.8 \pm 0.6 \mathrm{~mm}$ (range, $7.2-12.2 \mathrm{~mm})(P<$ 0.001 ) (Fig. 3) with a concomitant increase in the coarctation-to-isthmus diameter ratio from $0.45 \pm 0.06$ (range, $0.32-0.68$ ) to $0.78 \pm 0.03$ (range, $0.61-0.88$ ) $(P=0.002)$. There was no significant change in aortic diameter proximal to the coarctation following stent implantation $(12.8 \pm 0.3 \mathrm{~mm}$ vs. $12.1 \pm 0.6 \mathrm{~mm})$. The peak systolic gradient across the coarctation fell from $35.6 \pm 7.3 \mathrm{~mm} \mathrm{Hg}$ (range, $15-65 \mathrm{~mm} \mathrm{Hg}$ ) to $2.3 \pm 1.3$ $\mathrm{mm} \mathrm{Hg}$ (range, $0-10 \mathrm{~mm} \mathrm{Hg})(P=0.003)$. There were no acute aortic dissections or aneurysms identified by angiography (Fig. 4A).

Coarctation stent redilation. Stent redilation was performed $7.2 \pm 2.5$ mo following stent implantation. Animal weight had increased to $23.6 \pm 1.6 \mathrm{~kg}$ (range, $16.4-29.3 \mathrm{~kg}$ ), which represents a $74 \pm 7 \%$ increase in weight $(P<0.001)$. In one animal (Table II, animal 1), the distal stent extended into an area of marked poststenotic dilatation and was not well-apposed to the aortic wall, so that during angiography the angiographic catheter became entrapped through the stent and the stent could not be redilated. To avoid distortion of the stent or disruption of the aorta, no attempts were made to remove the angiographic catheter and the animal was sacrificed. The remaining 7 animals underwent stent redilation using 14- and 15-mm balloons, which yielded a balloon- 

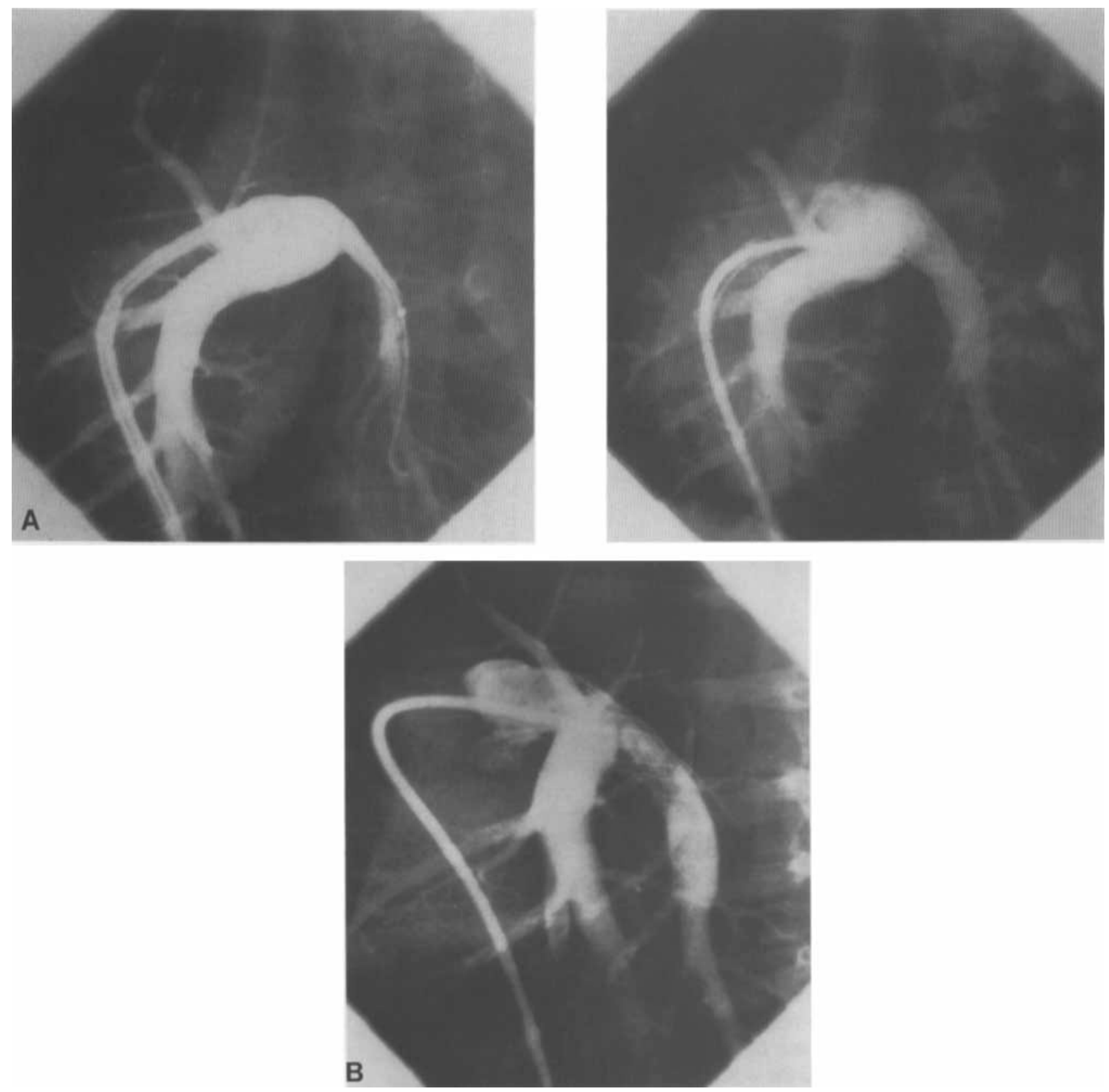

Fig. 2. A: Angiograms of animal with pulmonary artery stenosis prior to (lett) and following (right) endovascular stenting. The pulmonary artery proximal to the stent measured $5.4 \mathrm{~mm}$, and the stenosis was $3.4 \mathrm{~mm}$. The left puimonary artery proximal to the stenosis following stent implantation with a 9-mm balloon measured $9 \mathrm{~mm}$, and the stenosis was $6.3 \mathrm{~mm}$. The $10-\mathrm{mm} \mathrm{Hg}$ gradient across the left pulmonary artery was abolished by stent implantation. B: Three and a half mo following stent implantation, the stent was redilated with a $12 \cdot \mathrm{mm}$ balioon. The pulmonary artery proximal to the stenosis measured $10.4 \mathrm{~mm}$, and the stenotic segment was $8.1 \mathrm{~mm}$. A residual $8-\mathrm{mm} \mathrm{Hg}$ gradient was abolished by stent redilation. to-isthmus ratio of $1.02 \pm 0.02$ (range, $0.93-1.11$ ). The coarctation was redilated from $10.1 \pm 0.6 \mathrm{~mm}$ (range, $7.6-13 \mathrm{~mm}$ ) to $13.5 \pm 0.5 \mathrm{~mm}$ (range, $11.5-15 \mathrm{~mm})(P$ $=0.002$ ), and the diameter of the aorta proximal to the coarctation (at the proximal stent) increased from $12.1 \pm$ $0.5 \mathrm{~mm}$ (range, $10.4-14.8 \mathrm{~mm}$ ) to $14.5 \pm 0.3 \mathrm{~mm}$ (range, 14.1-15.2 mm) $(P=0.004)$ (Figs. 3, 4B). The coarctation-to-isthmus diameter ratio increased at redilation from $0.76 \pm 0.04$ (range, $0.6-0.9$ ) to $0.9 \pm 0.02$ (range, $0.88-1)(P=0.002)$. The residual peak systolic gradient across the coarctation decreased from $6.6 \pm 1.7$ $\mathrm{mm} \mathrm{Hg}$ (range, $0-13 \mathrm{~mm} \mathrm{Hg}$ ) to $0.4 \pm 0.4 \mathrm{~mm} \mathrm{Hg}$ 
TABLE I. Results of Pulmonary Artery Stent Implantation and Redilation

\begin{tabular}{|c|c|c|c|c|c|c|c|c|c|c|c|}
\hline \multirow[b]{2}{*}{ Animal no. } & \multirow{2}{*}{$\begin{array}{c}\text { Weight at } \\
\text { implantation } \\
(\mathrm{kg}) \\
\end{array}$} & \multicolumn{2}{|c|}{$\begin{array}{c}\text { LPA } \\
\text { stenosis (mm) } \\
\end{array}$} & \multicolumn{2}{|c|}{$\begin{array}{c}\text { Peak systolic pressure } \\
\text { gradient }(\mathrm{mm} \mathbf{~ H g})\end{array}$} & \multirow{2}{*}{$\begin{array}{l}\text { Weight at } \\
\text { redilation } \\
\quad(\mathrm{kg}) \\
\end{array}$} & \multicolumn{2}{|c|}{$\begin{array}{c}\text { LPA stenosis } \\
\text { redilation }(\mathrm{mm})\end{array}$} & \multicolumn{2}{|c|}{$\begin{array}{c}\begin{array}{c}\text { Peak systolic } \\
\text { pressure gradient } \\
(\mathrm{mm} \mathrm{Hg})\end{array} \\
\end{array}$} & \multirow[b]{2}{*}{ Comments } \\
\hline & & Pre & Post & Pre & Post & & Pre & Post & Pre & Post & \\
\hline 1 & 28.5 & 4.7 & 7.2 & 10 & 0 & 45.0 & 8.0 & 9.5 & $\mathbf{0}$ & 0 & \\
\hline 2 & 33.0 & 4.4 & 8.1 & 15 & 0 & 51.0 & 8.6 & 10.0 & 2 & & Redilated ex vivo \\
\hline 3 & 33.0 & 3.7 & 5.1 & 17 & 3 & 50.5 & 5.7 & 8.6 & 8 & & Redilated ex vivo \\
\hline 4 & 33.5 & 6.2 & 8.4 & 16 & 0 & 52.0 & 8.0 & 9.2 & 5 & 0 & \\
\hline 5 & 22.0 & 3.4 & 6.3 & 10 & 4 & 31.0 & 6.9 & 8.1 & 8 & 0 & \\
\hline 6 & 30.0 & 6.3 & 9.4 & 10 & 0 & 48.0 & 7.3 & 9.9 & 0 & 0 & \\
\hline Mean & 30.0 & 4.8 & 7.4 & 13 & 1.4 & 46.3 & 7.4 & 9.2 & 3.8 & 0 & \\
\hline SEM & 1.8 & 0.5 & 0.6 & 1.4 & 0.9 & 3.2 & 0.4 & 0.7 & 1.5 & & \\
\hline
\end{tabular}
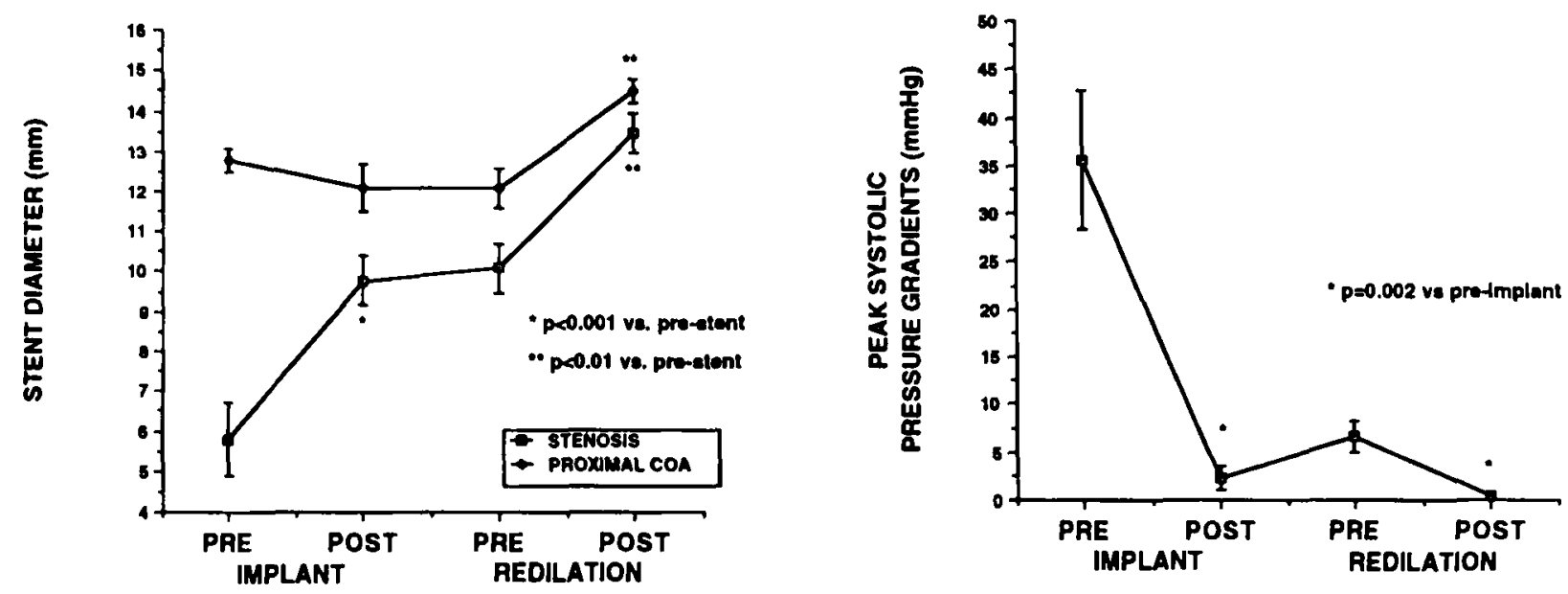

Fig. 3. Line graphs demonstrating changes in coarctation stent diameter (left) and systolic pressure gradient across the stent (right), following stent implantation and redilation. Proximal coa, aorta proximal to the coarctation. Stenosis, coarctation diameter.

(range, $0-3 \mathrm{~mm} \mathrm{Hg})(P=0.002)$. Stent length decreased from $27.0 \pm 0.4 \mathrm{~mm}$ to $24.5 \pm 0.5 \mathrm{~mm}(P=$ 0.003).

During stent redilation, 2 of the 7 animals (Table II, animals 2 and 5) had immediate and fatal aortic rupture during balloon inflation. There was no statistical difference between these 2 animals and the other 5 experimental animals in weight at implantation or redilation, time between stent implantation and redilation (7-10 mo), or redilation balloon pressure. Both the balloon/isthmus diameter ratio at stent redilation $(0.95 \pm 0.02$ vs. $1.04 \pm$ $0.02, P=0.03)$ and the coarctation diameters (7.8 \pm 0.2 vs. $11.1 \pm 0.6 \mathrm{~mm}, P=0.02$ ) in these 2 animals were significantly smaller than in the other 5 animals. The balloon/coarctation diameter ratios were significantly larger in the animals with aortic rupture than in the other 5 animals $(2.0 \pm 0.04$ vs. $1.4 \pm 0.01, P<0.01)$, and the percentage of increase in coarctation diameter following stent redilation was greater in the animals with aortic rupture $(59.8 \pm 6.0 \%$ vs. $26.6 \pm 8.5 \%, P=$ 0.07 ). There was no difference in stent length following redilation in the two groups. Autopsy revealed $2-3-\mathrm{mm}$ transmural tears $1-2 \mathrm{~mm}$ distal to the surgical coarctation suture line without disruption or fracture of the stent itself. The suture line itself appeared intact by gross inspection and microscopic study.

\section{Tissue Studies}

Pulmonary artery stents. Specimens were obtained by necropsy $1 \mathrm{mo}$ after stent redilation. There was complete neointimal coverage of the stent in all cases where there was full apposition of stent against the vessel wall. The neointima consisted of fibrous tissue covered by a thin endothelial cell layer (Fig. 5). There were small areas of medial calcification in 2 of the 6 pulmonary arteries, and microscopic hemosiderin in the media of 4 of the 6 pulmonary arteries reflecting old bleeding, possibly secondary to localized vessel trauma during stent implantation. However, there were no medial ruptures or aneurysms identified. In the 2 cases where the proximal stent extended freely into the main pulmonary artery 
$\mathbf{A}$

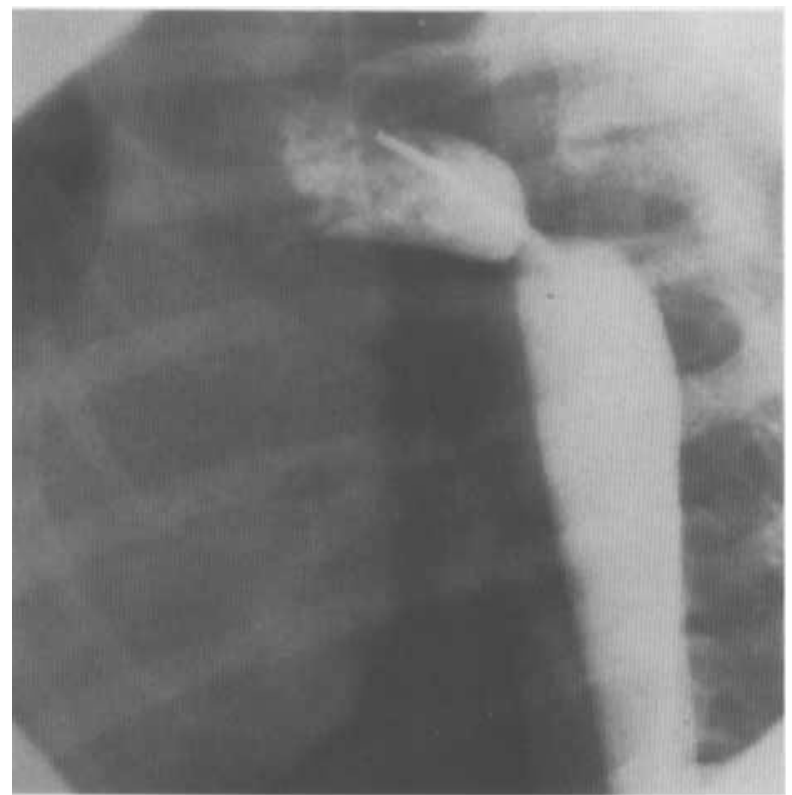

B

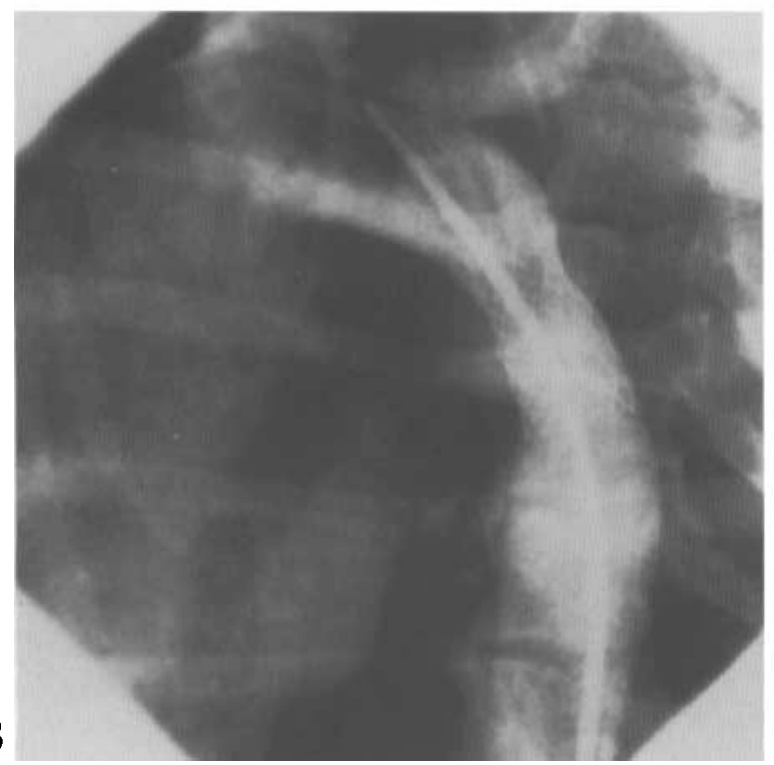

Fig. 4. A: Angiograms of animal with coarctation of the aorta, prior to (left) and following (right) stent implantation. Stenosis increased from $4.2 \mathrm{~mm}$ to $9.5 \mathrm{~mm}$ following stent implantation. The aorta proximal to the stenosis measured $12.5 \mathrm{~mm}$ both prior to and following stent implantation. Gradient reduction from 45 $\mathrm{mm} \mathrm{Hg}$ to $0 \mathrm{~mm} \mathrm{Hg}$ was achieved. B: Angiograms of animal with

there was incomplete neointimal coverage, and small, old, and organized thrombi were present on the nonendothelialized portions of the stent. In one stent explanted immediately following redilation, there were two shallow 2-3-mm intimal tears, with the remainder of the stent well-endothelialized (Fig. 6).

Coarctation stents. In the coarctation stents, there
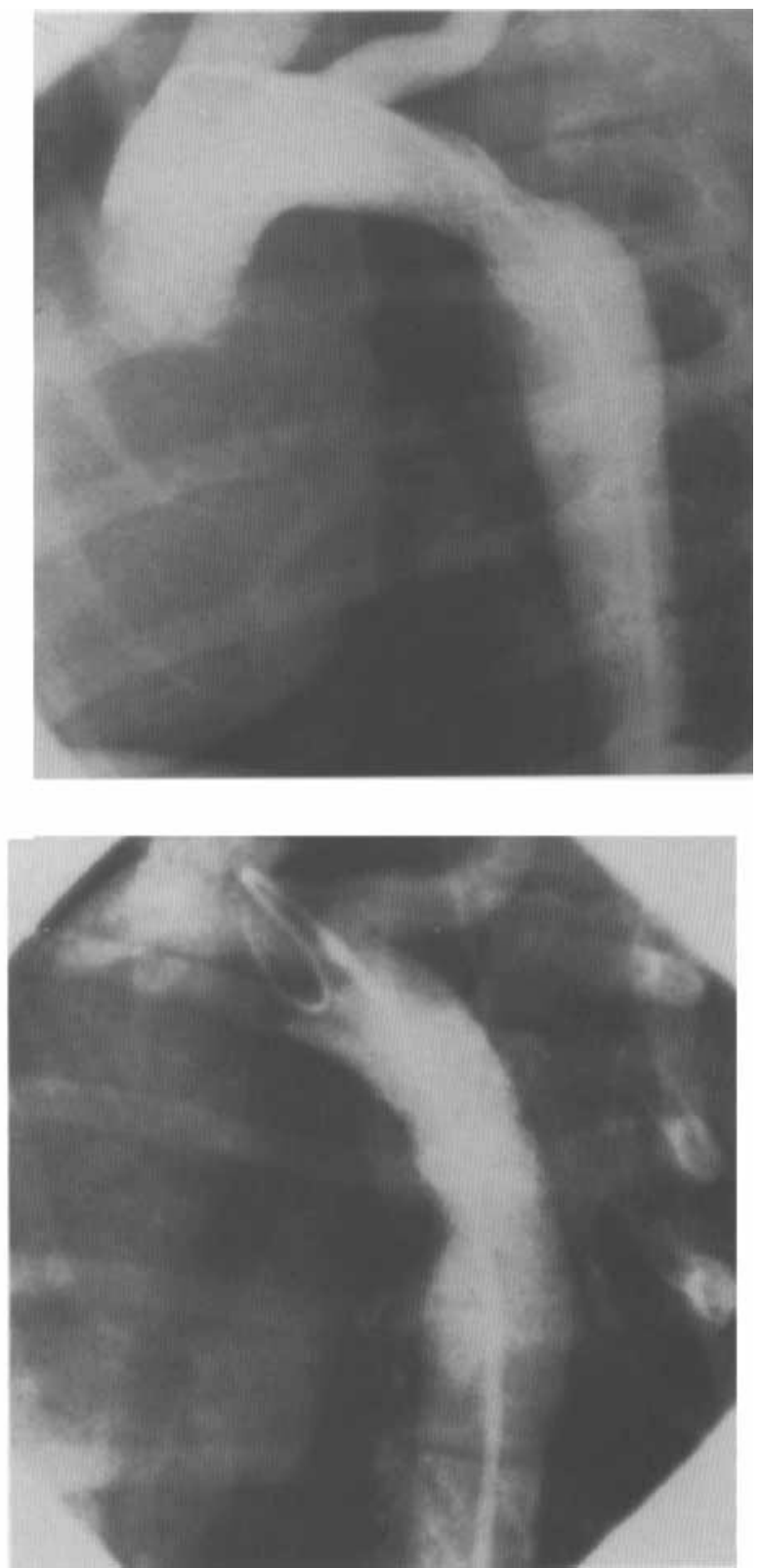

coarctation of the aorta prior to (left) and following (right) stent redilation. Stent redilation was undertaken 10 mo following stent implantation, using a balloon-10-isthmus diameter ratio of 1.1. Coarctation diameter was enlarged from 9.4 to $14.7 \mathrm{~mm}$, and proximal stent diameter increased from 12.5 to $14.9 \mathrm{~mm}$. A residual $5-\mathrm{mm} \mathrm{Hg}$ gradient was abolished at redilation.

was complete neointimal coverage of varying thickness when the stent was fully apposed to the aortic wall (Fig. 7). There was evidence of dystrophic calcification at the suture line. All tissues demonstrated microscopic hemosiderin in the media beneath the stent. There were no gross or microscopic thrombi, and no aortic aneurysms were identified. In the 2 animals with fatal aortic rup- 


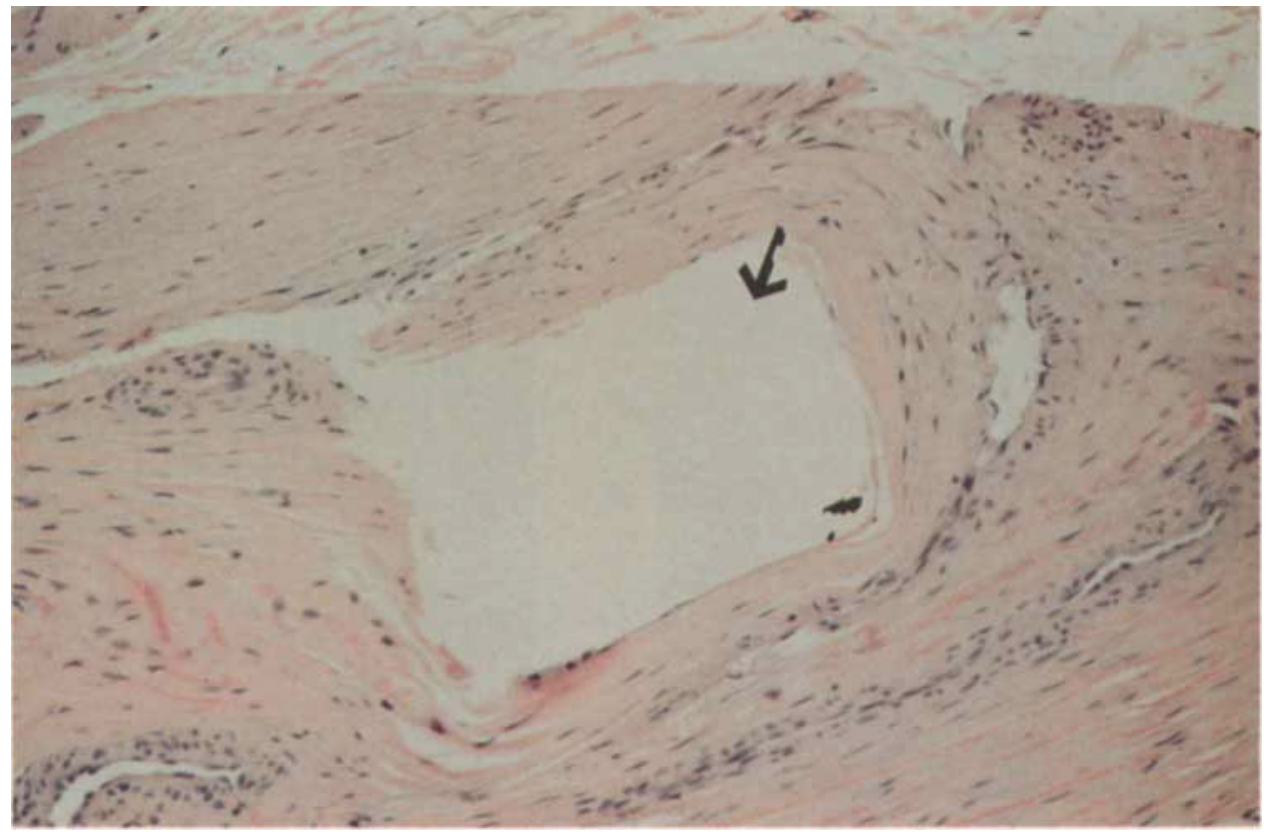

Fig. 5. H\&E stain of pulmonary artery 1 mo following stent redilation demonstrates a central defect, where the stent arm was located prior to its removal for tissue preparation. A thin neointima covers the area of the stent (arrow), composed of fibrous tissue and endothelial cells.

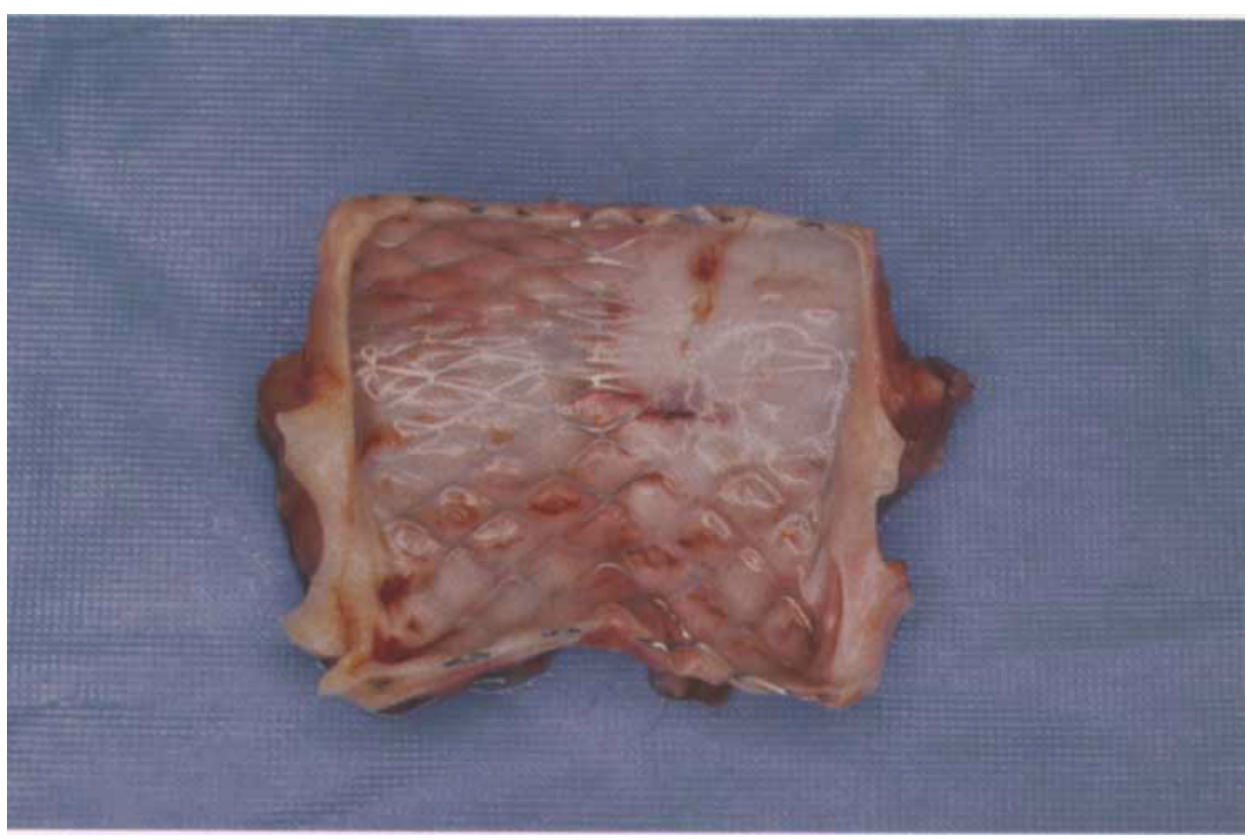

Fig. 6. Gross anatomical section following acute pulmonary artery stent redilation. There is a thin layer of neointima, and two 2-3-mm shallow intimal tears.

tures there was complete disruption of all layers of the aorta (Fig. 8), whereas the media in the remaining 5 animals was intact though thinned. One stent (which was not redilated for technical reasons) had incomplete neointimal coverage distally, where it was unapposed to the vessel wall in an area of marked poststenotic dilation. 

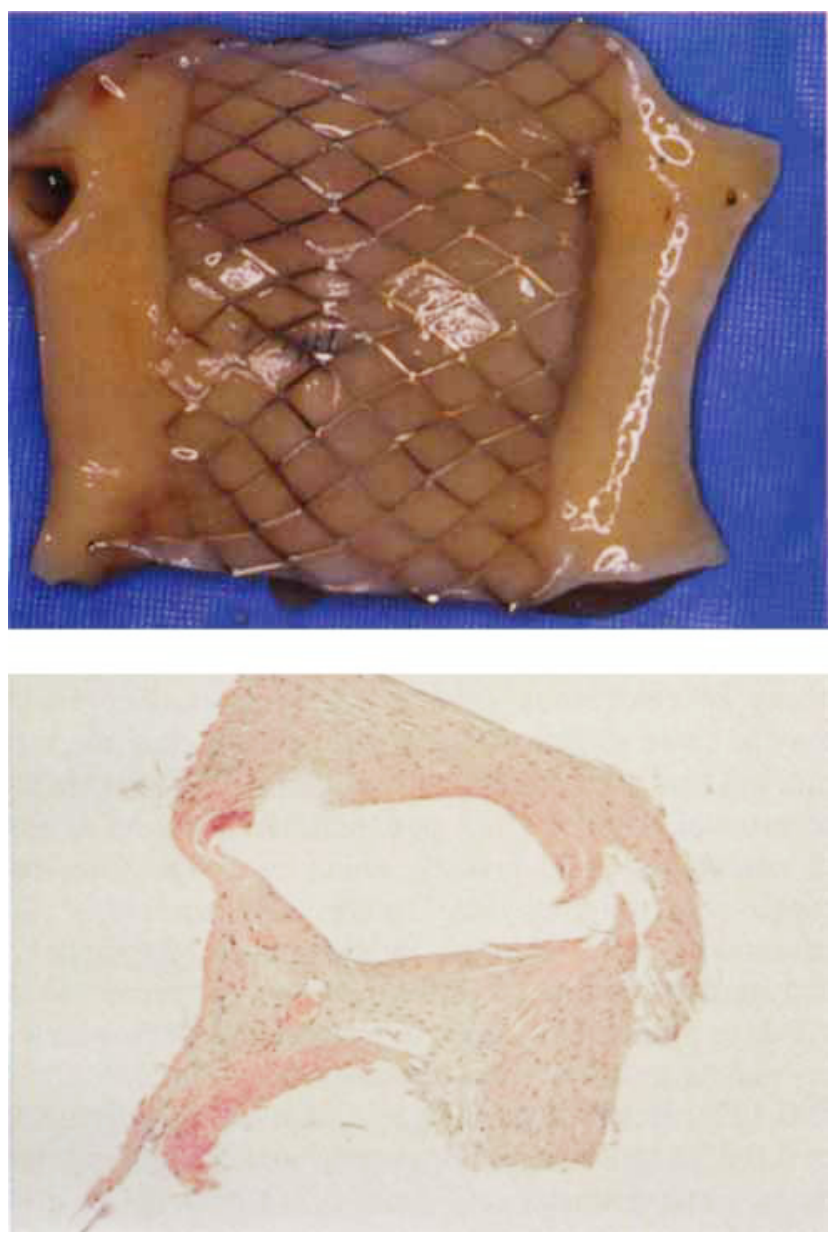

Fig. 7. Gross anatomy (above) and histology (below) of aortic coarctation 1 mo following coarctation stent redilation. Above: Stent is completely covered by a thin neointima, without evidence of tears or clots. Below: Thin neointima, with artifactual residua of stent wire and a small crescent of elastic lamina.

\section{DISCUSSION}

Though endovascular stent therapy for congenital heart disease has become a valuable tool for treatment of resilient vessel stenoses $[1-4,9,10]$, there remains concern over the utility of this therapeutic modality in young, growing children. This study is the first to show that stent redilation appears both safe and effective in an experimental model of peripheral pulmonary stenosis. Our study was limited by sample size. In 2 of the original 8 animals, resultant severe pulmonary artery hypoplasia from extensive banding precluded attempts at balloon angioplasty and thus stent implantation. This situation is not uncommonly seen in the clinical spectrum of severe pulmonary branch stenosis. Our study design and results are also somewhat limited, because stent redilation was performed based upon somatic growth of the animals and upon relative stent restenosis (when compared to the
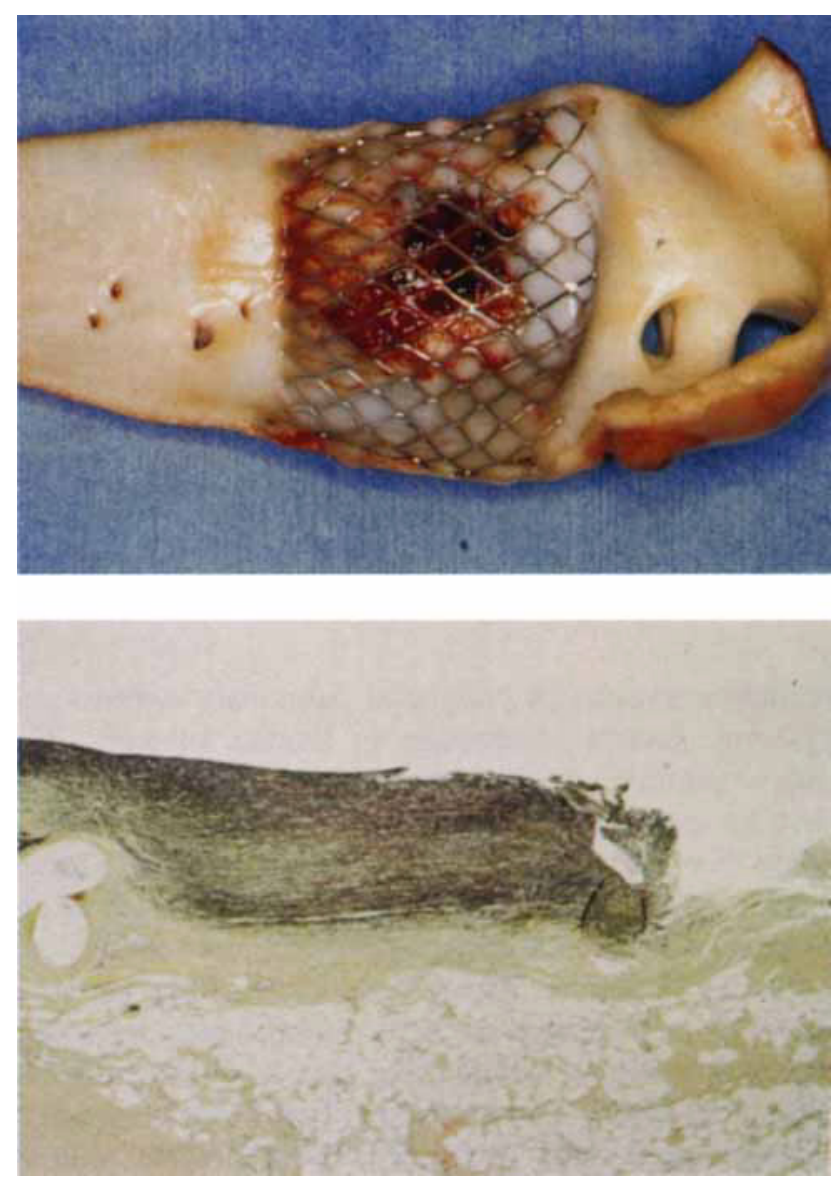

Fig. 8. Gross anatomical and histological changes following aortic rupture. Above: A 3-mm central transmural tear through the posterior wall of the aorta, without evidence of stent disruption. The remainder of the stent appears well-endothelialized. Below: Utilizing an elastic stain, the transmural rupture is identified in close proximity to a suture used to create the model.

proximal pulmonary artery) rather than true stent restenosis, which would be more analogous to the clinical situation. Lack of true stent restenosis may be intrinsic to this particular experimental model and, therefore, how these data translate into clinical practice cannot be fully determined. Still, in our canine model of peripheral pulmonary stenosis, we demonstrated that stents implanted at a stenosis diameter of $7.4 \pm 0.4 \mathrm{~mm}$ can eventually be redilated to $9.2 \pm 0.7 \mathrm{~mm}$, a $24 \%$ increase in diameter. There was histological evidence of shallow intimal tears acutely, without full-thickness vessel wall tears, which appeared to heal within $1 \mathrm{mo}$. There were no instances of aneurysms or distal vessel occlusion.

These data lend further experimental support to the clinical application of endovascular stent therapy in patients with pulmonary artery stenosis or hypoplasia. In the largest clinical trial to date, the multicenter study by O'Laughlin et al. [2] demonstrated feasibility of stent 
TABLE II. Results of Coarctation Stent Implantation and Redilation

\begin{tabular}{|c|c|c|c|c|c|c|c|c|c|c|c|}
\hline \multirow[b]{2}{*}{ Animal no. } & \multirow{2}{*}{$\begin{array}{l}\text { Weight at } \\
\text { implantation } \\
(\mathrm{kg})\end{array}$} & \multicolumn{2}{|c|}{$\begin{array}{c}\text { Coarctation } \\
\text { diameter }(\mathbf{m m}) \\
\end{array}$} & \multicolumn{2}{|c|}{$\begin{array}{l}\text { Peak systolic pressure } \\
\text { gradient (mm Hg) }\end{array}$} & \multirow{2}{*}{$\begin{array}{c}\text { Weight at } \\
\text { Redilation } \\
(\mathrm{kg})\end{array}$} & \multicolumn{2}{|c|}{$\begin{array}{l}\text { Coarctation diameter } \\
\text { redilation }(\mathrm{mm}) \\
\end{array}$} & \multicolumn{2}{|c|}{$\begin{array}{c}\begin{array}{c}\text { Peak systolic } \\
\text { pressure gradient } \\
(\mathrm{mm} \mathrm{Hg})\end{array} \\
\end{array}$} & \multirow[b]{2}{*}{ Comments } \\
\hline & & Pre & Post & Pre & Post & & Pre & Post & Pre & Post & \\
\hline 1 & 19.0 & 3.4 & 10.0 & 65 & 0 & 29.3 & 10 & & 10 & & Stent not redilated \\
\hline 2 & 12.9 & 3.7 & 7.5 & 15 & 0 & 21.4 & 8 & 12.3 & 0 & 0 & Aortic rupture \\
\hline 3 & 11.3 & 4.2 & 9.5 & 45 & 0 & 21.8 & 9.4 & 14.7 & 5 & 0 & \\
\hline 4 & 19.0 & 8.2 & 10.8 & 15 & 0 & 26.8 & 11.2 & 15.0 & 10 & 3 & \\
\hline 5 & 10.4 & 4.2 & 7.2 & 45 & 5 & 20.5 & 7.6 & 12.6 & 10 & 0 & Aortic rupture \\
\hline 6 & 12.7 & 5.1 & 11.0 & 60 & 10 & 23.2 & 11.4 & 13.7 & 13 & 0 & \\
\hline 7 & 15.4 & 9.5 & 12.2 & 15 & 3 & 29.1 & 13.0 & 14.7 & 5 & 0 & \\
\hline 8 & 9.5 & 8.2 & 10.1 & 25 & 0 & 16.4 & 10.5 & 11.5 & 0 & 0 & \\
\hline Mean & 13.8 & 5.8 & 9.8 & 35.6 & 2.3 & 23.6 & 10.1 & 13.5 & 6.6 & 0.4 & \\
\hline SEM & 1.3 & 0.9 & 0.6 & 7.3 & 1.3 & 1.6 & 0.6 & 0.5 & 1.7 & 0.4 & \\
\hline
\end{tabular}

redilation in cases of peripheral pulmonary stenosis and systemic venous obstruction in human subjects. The gross anatomic and histologic effects of stent redilation in these patients, however, were not reported. In our study there were small linear intimal tears (Fig. 6) seen acutely following dilation in one specimen, which appeared healed in the other specimens evaluated $1 \mathrm{mo}$ following redilation. These histologic findings are analogous to the anatomic and histologic changes previously reported following balloon angioplasty of experimental pulmonary artery stenosis [11]. In all cases of stent redilation in our study, there was medial integrity with no evidence of dissection or aneurysms.

This study also evaluated the role of stent implantation and redilation in an experimental model of coarctation of the aorta. In our study, the coarctation was dilated and stented from $5.8 \pm 0.9 \mathrm{~mm}$ to $9.8 \pm 0.6 \mathrm{~mm}$ in diameter $(P>0.001)$, with a similar increase in coarctation-toisthmus diameter ratio from $0.45 \pm 0.6$ to $0.78 \pm 0.03$ $(P=0.002)$. In one animal, the angiographic pigtail catheter became enmeshed in one of the side holes of the stent, making extrusion of the catheter from the stent (even with a wire) difficult, and thus this animal was sacrificed. This represents a potential technical issue with stent implantation in the aorta. Inadequate apposition of stent to aortic tissue may leave portions of the stent without neointimal covering, leading to catheter entrapment within the stent. All attempts should be made to implant the stent firmly in the aorta to avoid this problem. Unlike our experience with pulmonary artery stent redilation, however, redilation of coarctation stents was hazardous. There was a $28 \%(70 \% \mathrm{CL}=15-48 \%)$ acute mortality rate at stent redilation due to transmural aortic tears occurring in close proximity to the suture line. The high incidence of aortic rupture following stent redilation in our experimental coarctation model gives cause for concern. These data are not particularly consistent with clinical experience following balloon angio- plasty of coarctation (native, or postoperative, which may be more similar to our model), in which aortic rupture has been exceedingly uncommon $[12,13]$. Recently, Morrow et al. [6] created an experimental model of aortic coarctation in 11 juvenile swine by wedge resection, repair with polypropylene suture, and banding of the descending aorta. Cardiac catheterization, angioplasty, and implantation of PS 308 stents was performed $34 \pm$ 7.8 days following surgery with a resultant $96 \%$ increase in coarctation/aortic diameter ratio $(0.46 \pm 0.085$ to 0.9 \pm 0.122 ). Stent redilation in 5 animals was performed 59 \pm 6.0 days following implantation, increasing the coarctation/aortic diameter ratio from $0.774 \pm 0.121$ to 0.93 $\pm 0.11(P=0.02)$. These ratios are similar to those achieved in our series. By gross anatomic and histological examination following stent implantation and redilation, there were severe medial atrophy and aortic narrowing at the coarctation, but no significant aortic tears, ruptures, or thrombotic events.

In light of findings by Morrow et al. [6], we are concerned with the high incidence of aortic rupture in our model. The only significant difference in the creation of the model of Morrow et al. [6] and our own is primarily difference in species and, from a technical standpoint, addition of an aortic band following wedge resection. Still, in both animal models, there was histological evidence of medial atrophy, and in both, nonabsorbable suture was used to create the coarctation. In the porcine model, medial changes in the stent group were reportedly no different than those observed in a control group following coarctation creation. In addition, there were no significant changes in the neointima and media following both primary stent implantation and redilation. In our series, there was insufficient aortic tissue remaining in the two aortae which ruptured to ascertain whether there were similar degrees of medial atrophy when compared to the remaining 5 animals.

In a prior study, Morrow et al. [7] showed that over- 
expansion of endovascular stents implanted in growing normal porcine aortae leads to both longitudinal tears in the stent and the underlying aortic wall. Contrary to the findings in that study, aortic rupture in our animals was not associated with stent fracture or stent shortening, but rather solely with central transmural aortic tears. Review of some of the technical aspects of our experiment may shed greater light on these findings. Both the balloon/ isthmus diameter ratios and the coarctation diameters themselves in the animals with aortic rupture were significantly smaller at redilation when compared to the other experimental subjects, though the coarctation/isthmus ratios were not significantly different between the two animal groups either prior to $(0.66 \pm 0.06$ vs. 0.82 $\pm 0.04)$ or following $(0.88 \pm 0$ vs. $0.94 \pm 0.02)$ stent redilation. However, the balloon/coarctation diameter ratios in these 2 animals with aortic rupture were significantly larger than in the remaining experimental group, and the percentage of increase in coarctation diameter tended to be greater as well. These data suggest that there may be an absolute coarctation diameter below which stent redilation may be hazardous, or that stent redilation with balloon/coarctation diameter ratios $>1.4$ should be avoided.

It is possible that the high rate of aortic rupture observed in our study is an inherent problem of our experimental model. There were areas of dystrophic calcification noted along the suture lines, which may indicate structural weakness of the vessel wall. The aortic tears were in close proximity to the suture line, which was composed of nonabsorbable polypropylene sutures. The combination of "shearing force" by the redilated stent against the coarse, nonabsorbable sutures on the friable coarctation tissue may have led to this major complication. Our study is limited, because we did not examine the role of angioplasty alone in the resultant aortic tears. The implications of these findings to the clinical application of stent therapy in patients with coarctation are unclear. Caution is warranted, however, particularly in patients with postoperative recurrent coarctation, and more study of stent redilation is clearly necessary. Further histological studies need to be performed to evaluate intimal and media thickness both before and after stent implantation to determine if stent implantation leads to diminished smooth-muscle and fiber deposition (J.E. Lock, Personal communication).

In summary, we have shown in an experimental model of branch pulmonary artery stenosis that endovascular stent therapy appears safe at stent implantation and at redilation 3.8 mo after stent implantation. Complete neointimal coverage of these stents appears contingent upon full apposition between the vessel wall and the stent, as two stents which extended freely into the main pulmonary artery did not have complete neointimal cov- erage, and one stent in a dilated descending aorta led to catheter entrapment. Stent implantation in experimental coarctation of the aorta also appears safe, with excellent gradient reduction and expansion of the coarcted segment at initial implantation. In contrast to pulmonary artery stent redilation, however, redilation of coarctation stents was hazardous. We cannot predict outcomes of redilating significant stented stenoses from these data, particularly in the coarctation model, which best represents lack of stent/coarctation growth rather than significant stent restenosis. Certainly our data support the contention that possible overdilation or use of larger balloon/ coarctation diameters ratios may be hazardous in stent redilation. Redilation of these stents on the basis of somatic growth rather than recurrence of obstruction and increasing systolic gradients should be considered with care. Until the causes of our high rate of aortic rupture at stent redilation can be ascertained, we recommend stent implantation for coarctation of the aorta only in selected cases, where the patients are older and may not need stent redilation, or in cases where the patients are deemed poor surgical candidates, and standard balloon angioplasty is unsuccessful.

\section{ACKNOWLEDGMENTS}

The authors thank Mary Jo Riddell for assistance in preparing this manuscript. Dr. Mendelsohn was supported by National Research Service Award grant HL08709-01 from the National Heart, Lung and Blood Institute, National Institutes of Health, Bethesda, MD.

\section{REFERENCES}

1. O'Laughlin MP, Perry SB, Lock JE, Mullins CE: Use of endovascular stents in congenital heart disease. Circulation 83:1923$1939,1991$.

2. O'Laughlin MP, Slack MC, Grifka RG, Perry SB, Lock JE, Mullins CE: Implantation and intermediate-term follow-up of stents in congenital heart disease. Circulation 88:605-614, 1993.

3. Mendelsohn AM, Bove EL, Lupinetti FM, Crowley DC, Lloyd TR, Fedderly RT, Beekman RH: Intraoperative and percutaneous stenting of congenital pulmonary artery and vein stenosis. Circulation 88:210-217, 1993.

4. Ing FF, Grifka RG, Nihill MR, Mullins CE: Repeat dilation of intravascular stents in congenital heart defects. Circulation 92 : 893-897, 1995.

5. Beekman RH, Muller DWM, Lupinetti FM, Reynolds Pl, Heidelberger K, Mancini GBJ: Balloon-expandable stent treatment of experimental coarctation of the aorta: Early hemodynamic and pathologic evaluation. J Intervent Cardiol 6:113-123, 1993.

6. Morrow WR, Smith VC, Ehler WJ, VanDellen AF, Mullins CE: Balloon angioplasty with stent implantation in experimental coarctation of the aorta. Circulation 89:2677-2683, 1994.

7. Morrow WR, Palmaz JC, Tio FO, Ehler WJ, VanDellen AF, Mullins CE: Re-expansion of balloon-expandable stents after growth. J Am Coll Cardiol 22:1007-1013, 1993. 
8. Rocchini AP, Meliones JN, Beekman RH, Moorehead C, London $\mathrm{M}$ : Use of balloon-expandable stents to treat experimental peripheral pulmonary artery and superior vena caval stenosis: Preliminary experience. Pediatr Cardiol 13:92-96, 1992.

9. Benson LN, Hamilton F, Dasmahapatra $H$, Rabinowitch $M$, Coles JC, Freedom RM: Percutaneous implantation of a balloonexpandable endoprosthesis for pulmonary artery stenosis: An experimental study. J Am Coll Cardiol 18:1303-1308, 1991.

10. Mullins CE, O'Laughlin MP, Vick GW III, Mayer DC, Myers TJ, Kearney DL, Schatz RA, Palmaz JC: Implantation of balloonexpandable intravascular grafts by catheterization in pulmonary arteries and systemic veins. Circulation 77:188-199, 1988.
11. Lock JE, Niemi T, Einzig S, Amplatz K, Burke B, Bass J: Transvenous angioplasty of experimental branch pulmonary artery stenosis in newborn lambs. Circulation 64:886-93, 1981.

12. Beekman RH, Rocchini AP, Dick M, Snider AR, Crowley DC, Serwer GA, Spicer RL, Rosenthal A: Percutaneous balloon angioplasty for native coarctation of the aorta. J Am Coll Cardiol 10:1078-1084, 1987.

13. Mendelsohn AM, Lloyd TR, Crowley DC, Sandhu SK, Kocis KC, Beekman RH: Late follow-up of balloon angioplasty in children with a native coarctation of the aorta. Am J Cardiol 74:696$700,1994$. 